\title{
MITOLOGIA DOS ORIXÁS: MOSTRA ARTÍSTICA INTERDISCIPLINAR ENVOLVENDO ALUNOS DE LICENCIATURA
}

\author{
Simone Marques Braga (UEFS)* \\ Luciene Souza Santos (UEFS)** \\ Aaron Roberto de Mello Lopes (UEFS)***
}

\section{RESUMO}

Envolvendo estudantes de Licenciaturas diversas, essa experiência desenvolveuse a partir da criação e implementação de uma disciplina do Departamento de Educação da Universidade Estadual de Feira de Santana (UEFS) - Formação de Contadores de Histórias -, articulada com uma disciplina do Colegiado de Música da UEFS - História e Diversidade da Música Brasileira II. A primeira implementou os fundamentos da Arte de Contar Histórias no universo da Mitologia dos Orixás e introduziu conhecimentos básicos acerca da voz falada e cantada a partir do canto em Iorubá. A segunda enfatizou o trabalho com os toques rítmicos e cantigas dos cultos de matriz africana. A experiência interdisciplinar ainda contou com a colaboração de uma professora de teatro e um professor de dança afro que realizaram oficinas e ampliaram o repertório artístico dos estudantes. Buscou-se com essa experiência responder algumas inquietações: É possível desmistificar crenças e medos dos estudantes de Licenciaturas sobre a Mitologia dos Orixás? A partir de uma experiência estética sensorial de escuta e narração dessas histórias, é possível valorizar as relações étnico-raciais na universidade? Como desenvolver saberes pedagógicos e musicais envolvendo a matriz africana em uma licenciatura específica de música? Como resultado tivemos uma Mostra Performática cuja experiência cênica foi assistida por estudantes e professores de várias licenciaturas da Universidade, como também os processos formativos desta experiência foram abordados e discutidos através de uma roda de conversa.

Palavras-chave: Contação de histórias. Mitologia dos orixás. Ensino de música de matriz afro-brasileira.

* Doutora em Educação Musical pela Universidade Federal da Bahia (UFBA). Vice-Coordenadora do Colegiado de Música da Universidade Estadual de Feira de Santana (UEFS). Professora Adjunto e Coordenadora de Área do Pibid de Música (Musicando a Escola) da UEFS. Líder do Grupo de Estudos Contemporâneos em Música (UEFES). E-mail: moninhabraga@ gmail.com

** Doutora em Educação pela Universidade Federal da Bahia (UFBA). Vice-Coordenadora do Laboratório Interdisciplinar de Formação de Educadores (LIFE/UEFS). Professora Assistente e Coordenadora do Curso de Letras na modalidade a distância (UAB/UEFS). Membro do Grupo de Pesquisa FORMASER (UEFS). E-mail: lucienesantoz@gmail.com

${ }^{* * *}$ Doutor em Etnomusicologia pela Universidade Federal da Bahia (UFBA). Professor Substituto da UEFS. Membro do Grupo de Pesquisa GEMBA (UFBA). E-mail: aaronmlopes@gmail.com 


\section{ABSTRACT}

\section{MYTHOLOGY'S ORIXÁS: INTERDISCIPLINARY ARTISTIC SHOW INVOLVING TEACHING DEGREE STUDENTS}

Involving Students of diverse undergraduation degrees, this experience was developed from the creation and implementation of a discipline of the Department of Education of UEFS - "Formação de Contadores de Histórias" -, articulating that with a music collegiate discipline - "História e Diversidade da Música Brasileira II". The first one worked with the storytelling arts fundamentals on the universe of the Orixás Mythologies, and introduced the basic knowledge about the voice spoken and sung from the Yoruba's songs. The second one worked with the rhythms and chants of the african-borns cults. The interdisciplinary experience also had the collaboration of one theather teacher and one afro brazilian dance teacher, who developed workshops that expanded the students' artistic repertoire. It was tried with this experience to answer some restlessness: Is it possible to demystify beliefs and fears of undergraduate students about the Mythology of Orixás? From a sensorial aesthetic experience of listening and narration of the orixás stories, is it possible to value ethnic-racial relations in the university? How to develop pedagogical and musical knowledge involving the African matrix in a specific degree of music? As a result, we had a Performing Show whose scenic experience was attended by students and professors of several university degrees, as well as the formative processes of this experience were approached and discussed through a conversation wheel.

Keywords: History tells. Orixás mythology. Afro-brazilian music teach.

\section{RESUMEN}

\section{MITOLOGÍA DE LOS “ORIXAS”: MUESTRA ARTÍSTICA INTERDISCIPLINAR DE LOS ALUMNOS DE LICENCIATURA}

Con la participación de estudiantes de varios grados, esta experiencia ha desarrollado a partir de la creación e implementación de un curso en el Departamento de Educacão da UEFS- "Formação de Contadores de histórias" - en combinación con la disciplina del colegiado de música da UEFS - "História e Diversidade da Música Brasileira II). La primera implementan los fundamentos del arte de la narración de histórias del universo de la mitología de los Orishas e introdujeron el conocimiento básico de la palabra hablada y cantada desde el canto en Yoruba. El segundo hizo hincapié en el trabajo con toques rítmicos y canciones de los cultos de origen africano. La experiencia interdisciplinaria incluso con la colaboración de un profesor de teatro y maestro de danza africana que realizó talleres y amplió el repertorio artístico de los estudiantes. Buscado con la experiencia para responder a algunas preocupaciones: Usted puede desmitificar las creencias y los temores de estudiantes universitarios acerca de la mitología de los Orishas? A partir de una experiencia estética sensorial de escuchar y contar estas historias pueden valorar las relaciones étnicas y raciales en la universidad? El desarrollo de conocimiento educativo y musical que involucra las raíces africanas en un grado específico de la música? Como consecuencia, tuvimos un espectáculo performativo cuya experiencia escénica asistieron estudiantes y profesores de diversas titulaciones de la Universidad, así como el proceso de formación de este experimento fueron abordados y discutidos a través de una rueda de conversación.

Palabras clave: La narración de histórias, Mitología de los Orishas; enseñanza de la música de matriz afro-brasileña. 


\section{Introdução}

É possível desmistificar crenças e medos dos estudantes de Licenciaturas da Universidade Estadual de Feira de Santana (UEFS) sobre a Mitologia dos Orixás? A partir de uma experiência estética sensorial de escuta e narração dessas histórias, é possível valorizar as relações étnico-raciais na universidade? Como oportunizar a aproximação com a arte, a partir da música, na formação inicial de professores? Como desenvolver saberes pedagógicos musicais envolvendo a matriz africana em uma Licenciatura específica de música? Tais inquietações perpassam tanto a formação inicial, como a atuação de professores no contexto da educação básica, e emergem daí duas questões significativas, quais sejam: 1) diversidade cultural e as relações étnico-raciais intrínsecas; 2 ) a presença das artes na escola.

Tais questões estão presentes em políticas públicas e expressas nas Leis $\mathrm{n}^{\circ}$ 11.645/2008 (BRASIL, 2008) e no 13.278/2016 (BRASIL, 2016b), e na Medida Provisória ${ }^{\circ}$ 746/2016 (BRASIL, 2016a), que sinalizam para a responsabilidade das instituições de ensino superior de contribuir para a efetivação dessa legislação ao propor reflexões, discussões e ações que possam ser refletidas na formação de crianças e jovens no contexto escolar. Aos cursos de licenciatura, questões referentes à diversidade cultural, às relações étnico-raciais intrínsecas e à presença das artes devem ser incorporadas em suas práticas formativas ao desenvolver desde ações afirmativas a vivências na/pela arte.

De fato, essas leis são um grande avanço no sentido de reconhecer e valorizar a diversidade cultural, mas sua aplicação ainda é alvo de muitas incertezas: como desenvolver, na prática, ações pedagógicas afirmativas na universidade? Em cursos específicos de formação inicial de professores? Como abordar mitologias e práticas musicais discriminadas socialmente? Como lidar com os próprios preconceitos discentes? Com o objetivo de apresentar uma experiência pedagógica, envolvendo cursos de licenciatura da Universidade Estadual de Feira de Santana (UEFS), que buscou problematizar e responder as perguntas acima expostas, o presente artigo discorre sobre alguns aspectos investigativos que foram surgindo no processo de construção de uma mostra performática interdisciplinar a partir da temática Mitologia dos Orixás.

\section{Questões legais na inserção das relações étnico-raciais e artísticas na formação docente}

A presença das artes e do estudo de história e culturas afro-brasileiras e indígenas e relações étnico-raciais no âmbito educacional estão asseguradas legalmente e, como consequência, ambas devem ser consideradas na formação e atuação docente na escola, enquanto organização social que deva favorecer "princípios de igualdade básica da pessoa humana como sujeito de direitos" (BRASIL, 1991, p. 3). Baseado nestes princípios é direito de todos ter a sua condição racial e suas relações étnico-raciais respeitadas, assim como ter acessibilidade a práticas artísticas que valorizem a diversidade cultural, conforme estabelecidos nas Leis $n^{\circ} 11.645 / 2008$ (BRASIL, 2008) e $n^{\circ}$ 13.278/2016 (BRASIL, 2016b).

Tal direito não se limita ao acesso que o indivíduo deva ter a um ensino formalizado, mas que determinados bens e saberes devam ser considerados, a exemplo das práticas artísticas, asseguradas na Lei $\mathrm{n}^{\circ}$ 13.278/2016 (BRASIL, 2016b), que determina a obrigatoriedade do ensino de Música, Artes Visuais, Teatro e Dança. Sobre o ensino de música, o repertório, as atividades e as apresentações musicais realizadas na escola deverão ter caráter variado em consideração a esta acessibilidade e democratização da arte/cultura.

As apresentações escolares estão se constituindo como um espaço em potencial para o ensino das artes. Razão pela qual há divergência nas opiniões e concepções sobre as mesmas por parte dos professores e das respectivas escolas nas quais atuam. Enquanto muitas escolas priorizam a apresentação em eventos de datas comemorativas, como o fim de um processo de ensino e aprendizagem, muitos professores priorizam as suas potencialidades didáticas transformando-as em um meio para o desenvolvimento do ensino musical. De acordo com Sales (2014, p. 21-22), a apresentação musical

[...] pode motivar o aluno e fazê-lo socializar sua aprendizagem, compreender aquilo que conheceu 
ao longo do processo, aprender a trabalhar com o outro em grupo e desenvolver diversas habilidades musicais e artísticas dentro do âmbito escolar [...], entretanto, é preciso fugir da armadilha de reduzir o ensino de Música a essas atividades.

Nessa concepção, as apresentações podem transformar-se em instrumentos políticos de afirmação do ensino de arte nas escolas e em um espaço para o fomento do ensino das culturas afro-brasileiras e indígenas. Portanto, é imprescindível para determinados cursos de licenciatura, a exemplo dos responsáveis pela formação de professores das diversas artes, o fomento de performances artísticas para que a promoção e a função delas possam servir como ferramenta de formação, reflexão e discussão, visto que a realização de apresentações requer um entendimento que extrapola questões pedagógicas referentes ao ensino de artes, ao inferir questões referentes à gestão e à organização escolar.

Entendida como meio ou resultado de um processo de ensino e aprendizagem, as apresentações também podem explorar e envolver a história e cultura afro-brasileiras e indígenas. Almeida (2014, p. 18) considera que referenciar tais saberes

[...] trata-se da tarefa de todo e qualquer educador, independentemente do seu pertencimento étnico-racial, crença religiosa ou posição política. O racismo, segundo o Artigo $5^{\circ}$ da Constituição Brasileira, é crime inafiançável e isso se aplica a todos os cidadãos e instituições, inclusive à escola $[. .$.

Vale ressaltar que a recente Medida Provisória (MP) n ${ }^{\circ}$ 746/2016 (BRASIL, 2016a), que propõe a Reforma do Ensino Médio, através da institucionalização de Política de Fomento à Implementação de Escolas de Ensino Médio em Tempo Integral, reafirma o caráter obrigatório no currículo escolar da presença das culturas afro-brasileiras, indígenas, assim como do ensino das artes.

Contudo, mesmo com esse panorama pluricultural, sobretudo étnico, Gomes (2012) afirma que o (pre)conceito de raça ainda existente na sociedade brasileira é fruto de uma construção social que marca as sociedades latino-americanas, provenientes de um passado colonial que constituiu determinadas relações de preconceito racial presentes em todos os segmentos sociais, gerado por um processo histórico que discrimina determinadas etnias e culturas em nossa sociedade. Sansone (2003, p. 11) afirma que o preconceito de raça no Brasil está fundado sobre o mito de uma "democracia racial":

A democracia racial foi definida como o mito fundador das relações raciais brasileiras (Da Matta, 1987). Ou seja, trata-se de um mito aceito pela grande maioria, reproduzido na vida cotidiana, e que, em certo sentido, reflete uma realidade digna de análise antropológica e não pode ser tratado como se fosse uma farsa imposta de cima para baixo a fim de ocultar o racismo, ou uma espécie de falsa consciência (étnica) - tal como tem sido abordado com enorme freqüência pelos cientistas sociais (cf. Hanchard, 1994; Skidmore, 1974 e 1993; Winant, 1994). Nas classes mais baixas, esse mito popular coexiste com a minimização da diferença de cor nas práticas sociais, com momentos de intimidade extra-racial e com a criação de estratégias individuais destinadas a reduzir a desvantagem racial.

Portanto, percebe-se que o preconceito racial no Brasil pretende se invisibilizar por trás do mito da "democracia racial", que busca minimizar as diferenças raciais em prol de uma falsa igualdade racial. Estudos do Instituto Brasileiro de Geografia e Estatística (2016) apontam que o índice de analfabetismo, repetência e evasão são mais acentuados para os negros, razão pela qual alguns educadores (ALMEIDA, 2014; AMARAL, 1998; ROSEMBERG, 1998) têm se preocupado com as relações sociais estabelecidas em instituições educacionais, haja vista que podem reproduzir e intensificar as relações existentes em nossa sociedade. Nesta perspectiva, Almeida (2014, p. 18) afirma que:

O desenvolvimento de políticas afirmativas educacionais emerge da compreensão, de que a escola tem uma enorme responsabilidade na reprodução das desigualdades raciais e étnicas. Historicamente, o sistema de ensino brasileiro incutiu uma educação formal de embranquecimento cultural. A educação formal não era/é só eurocêntrica, ela também, ao mesmo tempo, desqualifica o continente africano, a cultura indígena e inferioriza racialmente os/as negros/as e índios/as. Isso acontece mesmo com a Lei de Diretrizes e Bases da Educação Nacional (9394/96) assegurando a igualdade de condições de vida e de cidadania, o direito às histórias e culturas dos diversos povos que compõem a nação brasileira, bem como, o acesso às diferentes fontes da cultura nacional a todos os brasileiros. 
Dessa forma, muitos são os desafios educacionais, como romper com esse histórico e avançar a partir da desconstrução de práticas educativas com perspectivas eurocêntricas que preservem a ideologia dominante. Todavia, abordar e lidar com essas diversidades nem sempre é uma ação fácil no âmbito das práticas pedagógicas adotadas na universidade, pois extrapola normas institucionais ao envolver crenças, formas de interação social e visões de mundo discentes. Tendo como um dos objetivos desconstruir a discriminação e os preconceitos entre os estudantes, o presente artigo apresenta uma experiência desenvolvida na Universidade Estadual de Feira de Santana, que teve como principais propositores os componentes curriculares Formação de Contadores de Histórias e História e Diversidade da Música Brasileira, ofertados para os cursos de Licenciatura em Letras, Música e Pedagogia.

\section{Formação de Contadores de Histórias e Música: uma experiência interdisciplinar}

O contador de histórias, em seu ofício, apresenta, através de suas narrativas, posicionamentos a favor da cidadania - a exemplo do respeito pelos direitos humanos, pelas questões de gênero e pela diversidade, que tanto demarcam a luta das minorias -, e faz isso porque tem como matéria-prima a sabedoria ancestral, que se baliza pela justiça.

As narrativas orais integram, socializam, aproximam os diferentes. Por isso, é importante que a função de professor coexista com a de contador de histórias. Quando revestido de contador de histórias, com verdades herdadas de seu repertório de contos e de posse das qualidades estéticas da arte da contação, o professor tem condições de interagir com o outro em seus processos de narração e de escuta de si. Professor e contador de histórias desenvolvem seu ofício de gente para gente, com gente - as pessoas com quem necessariamente têm de interagir para fazer circular informações e saberes, produzir conhecimentos e constituir valores.

Sabemos que nas sociedades de tradição oral os contadores de histórias fazem uso da palavra em sua dimensão educativa. E fazem isso através da oralidade, reconhecida por eles como o principal veículo de transmissão de saberes. Hoje, porém, o contador de histórias tem consciência de que o sujeito já nasce imerso na sociedade da escrita, influenciado por uma oralidade secundária, na expressão de Ong (1993), fortemente demarcada por suportes tecnológicos que difundem voz e imagem em dimensões diversas. Eis aí o desafio de quem tem a pretensão de educar através das histórias. Nesse sentido, um professor, quando é também um contador de histórias - tomado pelo desejo e vontade de querer revelar sua condição de narrador, "uma vocação", na perspectiva de Rubira (2006, p. 18) -, habilita-se para alcançar essa dimensão educativa da palavra:

Falamos de uma vocação não no sentido de se ter um dom dado pronto e acabado que, portanto, dispensa qualquer esforço para que se usufrua dele, mas no sentido mesmo de um chamamento (vox anima), ao qual não se pode ignorar porque ele grita em nós, clama por nós, reclamando-nos uma ação. Há de se ter dentro de si uma grande vontade de se comunicar com o outro, de partilhar ações comuns que resultem no aprendizado, no ensinamento desse outro.

Professores e contadores de histórias são guardiões da palavra e, quando se misturam, constroem, através das narrativas, um movimento de fala e escuta entre os seus interlocutores - seus alunos. Quando descobrem quem é o contador de histórias que mora em si, fazem-se portadores de toda sorte de gestos culturais e palavras. O professor e o contador se aproximam da essência do narrador ancestral que habita em cada um. Através da memória afetiva, eles vão revelando as histórias fundantes que lhes marcaram a vida e revelam o seu gosto pelas narrativas. E, para isso, não há receitas nem fórmulas, tampouco um jeito milagroso que provoque esse híbrido. O que há é um caminho metodológico composto por modos de narrar que saíram dos livros de outros contadores de histórias, é o repertório e a performance de contadores que se apresentam em espaços diversos, é o processo de descoberta desse narrador que mora em cada um na sua ancestralidade, o que se revela através de um estilo pessoal que provoca e visibiliza potencialidades encobertas.

Educar alguém é introduzi-lo, iniciá-lo numa certa categoria de atividades que se considera como 
dotadas de valor [...], não no sentido de um valor instrumental, de um valor como meio de alcançar uma outra coisa (tal como o êxito social), mas de um valor intrínseco [...] Ou ainda é favorecer nele o desenvolvimento de capacidades e de atitudes que se consideram como desejáveis por si mesmas, é conduzi-lo a um grau superior [...] de realização (FORQUIN, 1993, p. 65).

Assim como o contador de histórias educa através das histórias e da relação que elas constituem com seus ouvintes, o professor também educa através da relação pedagógica estabelecida com seus alunos. Partindo dessa premissa, desenvolvemos, através do componente curricular "EDU 925 - Formação de Contadores de Histórias: Conta Comigo!", procedimentos que se colocaram no território do ensino e da contação de histórias e desencadearam em nós o desejo de educar na perspectiva aqui descrita por Forquin (1993).

O caminho metodológico aqui delineado para estruturar a oferta de EDU 925, em caráter optativo, no primeiro semestre de 2016 , foi planejado a muitas mãos, mais diretamente pelas professoras Santos e Braga. A primeira, responsável pela formação dos contadores de histórias (teoria e prática) e a segunda, responsável pela construção performática e pelo repertório cantado em iorubá, que deram sustentação às histórias contadas pelo grupo. Além delas, o professor Aaron Lopes, responsável pela disciplina "LET 693 - História e Diversidade da Música Brasileira II" - assumiu o trabalho percussivo que deu origem a boa parte da trilha sonora que sustentou o produto final dessas disciplinas, a Mostra Performática: Mitologia dos Orixás.

Enquanto o primeiro componente propôs a formação de contadores de história articulada à formação inicial de professores, o segundo oportunizou a articulação desta formação com a mitologia dos Orixás, através do diálogo entre educação musical e etnomusicologia que buscou uma formação que valorizasse a diversidade.

A etnomusicologia e a educação musical, até pouco tempo atrás, pouco dialogavam. A etnomusicologia tradicionalmente aproximava-se de áreas como antropologia e sociologia, enquanto a educação musical buscava um ensino de música com foco nos processos de ensino/aprendizagem de modelo eurocêntrico (QUEIROZ, 2005).
Contudo, nos últimos anos, ambas têm buscado cada vez mais aproximar o seu campo de atuação, ampliando e enriquecendo as suas práticas a partir dessa aproximação: “A Educação Musical talvez seja o caminho no qual a etnomusicologia se torne mais relevante, e onde ela pode se revolucionar" (CAMPBELL, 2003, p. 33).

Enquanto, tradicionalmente, estuda culturas orais ou tradicionais (no Brasil, com um foco nas culturas negras, indígenas, caboclas e de religiosidade popular), uma importante contribuição que a etnomusicologia tem a oferecer para a educação musical é a compreensão da música como fenômeno resultado de sistemas culturais, os quais ela reflete e é refletida. Segundo Queiroz (2005, p. 50):

Essa perspectiva tem conduzido importantes reflexões no campo da educação musical, levando-nos a compreender que um ensino significativo deve entender esse fenômeno não só como expressão artística, mas, principalmente, como manifestação representativa de sistemas culturais determinantes do que o homem percebe, pensa, gosta, ouve, sente e faz.

Partindo dessa premissa, a etnomusicologia questiona a forma tecnicista e com o foco excessivo na partitura - maneira mais comum em que a música é transmitida na sociedade ocidental. Segundo Nettl (2005), é muito importante um ensino mais plural, que busque enriquecer a experiência musical dos alunos através de novos olhares e novas maneiras de ensinar e tocar música:

Nós queremos que nossos estudantes, acima de tudo, e de todos os níveis, sejam capazes de se localizar no amplo espaço cultural, histórico e musical. A descobrir a incrível diversidade de ideias que há no mundo sobre a música e os sons musicais, o que, me parece, é a atitude mais interessante dos professores para com as crianças, bem como das crianças que existem em todos nós (NETTL, 2005, p. 403).

Portanto, Nettl (2005) acredita que o etnomusicólogo pode contribuir profundamente com a experiência de aprendizagem dos seus alunos através desse olhar para novas práticas de ensino. Nesse momento, buscando um papel de maior protagonismo nos processos de ensino/aprendizagem, a etnomusicologia tem contribuído cada vez para uma educação musical "deselitizada” (QUEIROZ, 2005). 
Levando em consideração as trocas culturais entre professores e alunos, Swanwick (2003) afirma que a música atua em um "espaço intermediário", unindo o indivíduo à cultura, onde acontecem as interações sociais e as trocas simbólicas. Para ele, "[...] a interação social conosco e com os outros efetiva-se por meio dos sistemas simbólicos" (SWANWICK, 2003, p. 41). Pensando nessas questões para os processos educativos, afirma que

O ensino musical, então, torna-se não uma questão de simplesmente transmitir a cultura, mas algo como um comprometimento com as tradições em um caminho vivo e criativo em uma rede de conversações que possui muitos sotaques diferentes. Nessa conversação, todos nós temos uma 'voz' musical e também ouvimos as 'vozes' musicais de nossos alunos (SWANWICK, 2003, p. 46).

Esse ponto de vista é compartilhado por Kleber (2014) e Hikiji (2006), que pesquisaram sobre a prática de ensino musical em ONGs e espaços de educação musical comunitária. Para ambas as autoras, o fenômeno social deve ser entendido a partir da maior gama possível de variantes, como um "enorme conjunto de fatos muito complexos" (KLEBER, 2014. p. 34). Nesse sentido, é preciso analisar as mais diversas instituições possíveis - religiosas, políticas, morais, econômicas e estéticas - e buscar um ensino não elitista, que valorize a identidade individual e coletiva do grupo de alunos - as suas "vozes", como afirma Swanwick (2003).

Portanto, ainda que Swanwick (2003) reconheça que a educação musical tem avançado muito nessas questões, abordar uma educação musical que valorize a diversidade ainda é um grande desafio em busca de uma formação não hegemônica. Sobre isso, Queiroz (2005, p. 60) afirma que “[...] o reconhecimento da diversidade nos fez perceber que não existe uma única música e/ou sistema musical, e que, portanto, não podemos ter uma educação musical restritiva e unilateral". Contudo, para Queiroz (2005), isso não significa simplesmente inserir músicas populares ou de expressões musicais de tradição oral. É preciso também mudar a metodologia de ensino:

A inserção da música popular, ou de práticas musicais que têm como base expressões musicais de tradição oral, em grande parte das propostas que temos assistido nos sistemas de ensino institucionalizados se dão por processos semelhantes aos de transmissão da música 'erudita'. [...] Precisamos evidenciar na educação musical que, de fato, o que importa não é o transplante musical de estruturas desprovidas de significado, mas sim uma verdadeira contextualização das propostas de ensino com músicas diversificadas, em que sejam considerados os valores e as relações mais amplas de cada manifestação, inserindo a prática educativo-musical no universo global das diferenciadas realidades (QUEIROZ, 2005, p. 61).

Sendo assim, a inserção de músicas de cultura oral, sobretudo negras e indígenas, defendida em leis e documentos (BRASIL, 2008, 2016a, 2016b), deve ir além do conhecimento e compreensão de conceitos, documentos e leis acerca das relações etnorraciais. As vivências musicais dessas culturas devem ser acompanhadas de uma profunda discussão, reflexão e, consequentemente, transformação na formação dos professores de música, para que sejam capazes de lidar com situações presentes no ensino de música na escola, quais sejam: 1) o preconceito acerca de determinados repertórios e instrumentos musicais; 2) o mito em torno da execução de determinados instrumentos, a exemplo de tambores; 3) o mito da associação desses instrumentos com o que erroneamente são denominados como provenientes de "música de macumba".

Segundo Santiago e Ivenicki (2016, p. 201), é preciso verificar como estão sendo preparados os professores para

(1) lidar com diferenças de raça, etnia, gênero, sexualidade e musicalidade dentro das salas de aula; (2) ministrar uma educação musical heterogênea, que respeite as diferentes culturas e musicalidades; (3) evitar o preconceito e a discriminação e (4) atuar positiva e competentemente, caso algum desses fenômenos sociais negativos ocorra nas escolas.

Nesse sentido, a inclusão de práticas musicais afro-brasileiras em cursos de formação não só atenderá o respeito e dissolução de preconceitos e discriminações, mas aproximará os licenciandos de musicalidades negras, formas de execução e aprendizagens, o que oportunizará que possam contemplar essas musicalidades em suas práticas. Essa 
aproximação também favorecerá o conhecimento de processos de ensino e aprendizagens diferenciados. Tais processos ampliarão as referências dos licenciandos em formas de aprender e ensinar música, as quais serão enriquecedoras em se tratando de um contexto tão complexo como a escola.

De acordo com Doring $(2015$, p. 1), as abordagens adotadas na escola formal ainda focam a música "[...] como 'produto', de forma distante da complexidade das tradições orais de matrizes afro-brasileiras, ameríndias e lusófonas". Segundo essa autora, ainda são poucas as pesquisas sistematizadas sobre o aprendizado na tradição oral. Desta forma, a presente experiência possibilitou considerar estas questões por meio da ampliação da formação pedagógica musical dos futuros professores, reforçada sobretudo no componente História e Diversidade da Música Brasileira II, como será descrito a seguir.

\section{História e Diversidade da Música Brasileira II e a formação do grupo musical}

Para complementação da parte musical da mostra, foi formado um grupo com alunos da disciplina "LET693 - História e Diversidade da Música Brasileira II" (HDMB II). Esta é uma disciplina do curso de licenciatura em música da UEFS, de caráter obrigatório e restrita a alunos regulares do curso. O grupo foi composto por 8 alunos, além de uma aluna que não estava matriculada na disciplina, mas que pediu para participar da mostra.

A disciplina HDMB II é uma disciplina teórica que aborda a história da música brasileira a partir do início do século XX e que tem como conteúdo programático a abordagem de processos históricos da música popular brasileira, da música erudita e também de culturas populares, predominantemente orais. Portanto, apesar de ser uma disciplina que tem como objetivo a abordagem de uma história da música com foco na música urbana e letrada, contempla também a diversidade de culturas musicais, o que torna possível uma busca por outras histórias - não-oficiais, orais, rurais, diversificadas. Nesse sentido, a disciplina pode alinhar-se à abordagem de conteúdos afro- -brasileiros e indígenas - e contempla também as Leis $\mathrm{n}^{\circ} 11.645 / 2008$ (BRASIL, 2008) e $\mathrm{n}^{\circ}$ 13.278/2016 (BRASIL, 2016b).

Durante o cursar da disciplina, portanto, além do conteúdo historiográfico "canônico" e "oficial", abordamos também muitos temas relacionados à diversidade cultural e musical, tais como: sexualidade na música brasileira; conflitos de raça e classe na música brasileira; culturas musicais de matriz africana e indígena; música brasileira e gênero; preconceito musical; dentre outros temas. Portanto, a possibilidade de realizar uma mostra com músicas de candomblé com o grupo de alunos da disciplina foi uma oportunidade única do grupo vivenciar esse repertório e enriquecer o seu aprendizado sobre a importância da diversidade cultural na história da música brasileira.

Um fato que merece grande destaque foi quanto à configuração do grupo de alunos que, de fato, era um grupo de grande diversidade cultural e religiosa: a turma foi formada por um aluno indígena, um aluno capoeirista e candomblecista, um aluno ativista da causa LGBTT e quatro alunos evangélicos. Portanto, o grupo refletia toda a diversidade que a disciplina se propõe a abordar.

De fato, as religiões afro-brasileiras têm sofrido muitos ataques de grupos radicais - no Rio de Janeiro, por exemplo, muitos terreiros e praticantes têm sido expulsos dos morros por traficantes neopentecostais (SOARES, 2013). Essa tensão é refletida também na UEFS, cujo grupo de alunos evangélicos é muito grande. Todavia, é importante frisar que os evangélicos são um grupo muito diverso de religiosos, e esses atos de preconceito são praticados por grupos mais radicais - notadamente grupos neopentecostais. Nesse sentido, é de suma importância frisar a convivência pacífica do grupo de alunos evangélicos da disciplina durante todo o processo. Esses alunos, a maioria praticantes da religião batista, foram consultados e aceitaram participar do trabalho e não se mostraram resistentes ao seu desenvolvimento, diferentemente do grupo de alunas evangélicas da disciplina de contação de histórias descrito acima. Muito pelo contrário, todos eles participaram ativamente do grupo musical, dos ensaios e da apresentação e mostraram-se bastante ativos e interessados em aprender e respeitar a 
diversidade cultural e religiosa. Acreditamos que o fato da disciplina buscar o diálogo com as culturas afro-brasileiras tenha ajudado nessa convivência respeitosa.

Esse diálogo foi oportunizado a partir do trabalho com a música de candomblé. Esta é notoriamente reconhecida, pelos alunos do curso de música da UEFS, como uma música de grande complexidade rítmica e melódica, devido ao fato de ela não se adequar aos moldes da música tradicionalmente ensinada nos cursos de licenciatura - que tem um foco na música ocidental europeia e norte-americana. Nesse sentido, além de existir uma grande lacuna conceitual dos alunos sobre essa música, há uma grande dificuldade desse grupo de aprender e executar seus ritmos e cânticos.

Para o desenvolvimento da mostra, portanto, foi necessária uma sondagem de toques cujo ritmo fosse menos complexo para o aprendizado e execução do grupo de alunos em questão. Nessa busca por toques menos complexos, o grupo executou o "agueré", o "alujá", o “ijexá", e a "ramunha" - este último um ritmo um pouco mais complexo.

É importante complementar que no candomblé a música desempenha diversos usos e funções e cada orixá tem o seu repertório específico de cantigas e toques. Lühning (1990, p. 119) descreve 17 dessas funções, que vão desde "rituais preliminares das festas e ocasiões que não são públicas", a momentos específicos da festa, como "cantigas do xirê" (quando não há orixá manifestado), "cantigas de chamar o santo", "primeira de dar o rum" (para saudar o orixá recém-manifestado), "cantigas de rum" (para os orixás manifestados), "cantigas de fundamento" (para chamar outros orixás) e "cantigas de maló" (de despedida aos orixás).

Como a mostra não possuía um caráter sacro, as cantigas e toques foram executados de maneira livre, mas com muito respeito à liturgia e aos orixás. Buscou-se por cantigas cuja execução não é restrita aos rituais e pode ser executada publicamente sem a obrigatoriedade de cumprir com as funções rituais. Além disso, devido ao fato da mostra buscar homenagear e contar histórias de todos os orixás, a ordem dos toques e cantigas também respeitou o repertório de cada orixá - por exemplo, o "agueré" foi executado para Exu e Oxossi; o "alujá", para Xangô, e assim por diante.

Além dos toques, foram executadas pelo grupo de alunos três cantigas, cada uma homenageando um orixá, em momentos específicos da apresentação. Foram cantadas "Esú ojú ô màmá", homenageando Exu, "Oro Mi maió", homenageando Oxum, e "Aruê Babá", saudando Oxalá. Para os outros orixás foram executados apenas seus toques específicos, ou cantigas já popularizadas pela música popular, como as músicas "Ponto de Nanã" e "Canto de Oxossi", compostas por Roque Ferreira, e "É d'Oxum" do compositor baiano Gerônimo, como número final da mostra. Essas canções foram cantadas pelos alunos da disciplina de Formação de Contadores de Histórias, e o grupo de HDMB II apenas construiu e executou o arranjo instrumental. Além destas músicas, foi executada também a canção “Aie, N’Toto, nile”, composta por Sergio Souto, que não se refere a nenhum orixá especificamente, mas que remete ao universo musical afro-brasileiro.

O grupo instrumental tradicional das músicas de candomblé é formado por um trio de atabaques - rum, rumpi e lê - e agogô. Entretanto, dada a configuração do grupo de alunos e a falta de instrumentos tradicionais (tínhamos apenas um atabaque e um agogô), o conjunto instrumental foi formado a partir dos instrumentos próprios dos alunos, os quais eles já têm familiaridade e destreza de execução. Na turma, somente dois alunos tinham familiaridade com os ritmos de candomblé - e um deles, candomblecista, foi o responsável por trazer e tocar o atabaque, instrumento que executa os ritmos mais complexos. Além do atabaque e do agogô, o conjunto instrumental contou com berimbau, teclado, violão, clarinete, pandeiro, caxixis e instrumentos percussivos a partir de materiais reciclados, construídos durante a ofina de canto coletivo.

Portanto, a execução das cantigas não buscou ser fiel à execução sacra. Antes, o estudo dos toques e cantigas propiciou ao grupo de alunos vivenciar a música de candomblé e, com base em suas próprias experiências em música, criar e executar arranjos a partir do repertório de candomblé. 
Figura 1 - Participação dos estudantes do componente LET 693

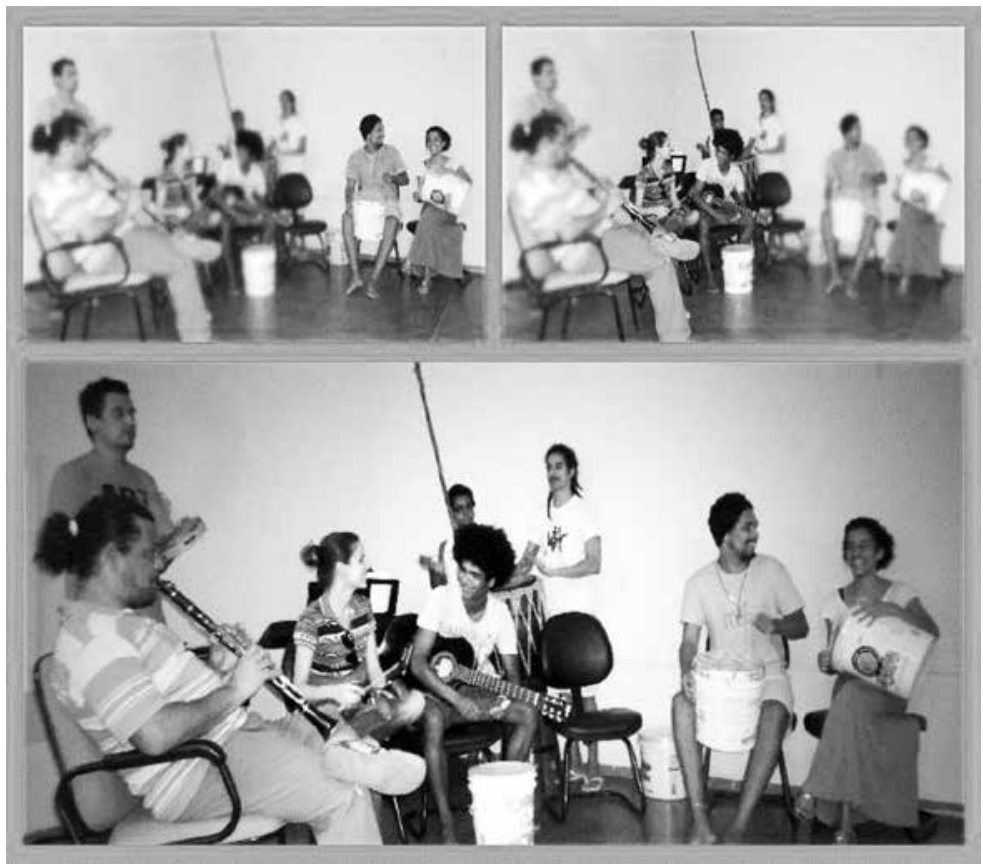

Fonte: Acervo pessoal dos autores.

O processo de aprendizado, construção coletiva de arranjos e execução dos toques e das cantigas de candomblé acima citados demonstrou para os alunos de licenciatura em música e os demais alunos envolvidos na mostra performática que é possível e necessária a inserção desse repertório nas suas práticas musicais docentes. Os toques de candomblé possuem uma grande variedade de complexidade, o que torna possível o seu aprendizado a uma ampla variedade de alunos, de turmas iniciantes a avançadas, e a busca pelo conhecimento desses novos repertórios é de grande importância para uma formação musical ampla e sem preconceitos por parte dos discentes.

\section{O desenvolvimento de oficinas}

Além dos três professores envolvidos, foram convidados outros profissionais para fazer parte do corpo docente, para ministrar oficinas que trabalhassem fundamentos importantes para a composição da Mostra: um professor de dança afro e uma professora de teatro. Sendo assim, a proposta para a disciplina de natureza optativa, com 60 horas de carga horária, foi organizada no formato de oficinas.
Metade da carga horária foi destinada aos fundamentos teórico-práticos da arte de Contar Histórias, cerca de 30 horas, e as demais foram destinadas à escolha e preparação do repertório para a Mostra Performática: Mitologia dos Orixás. Durante o desenvolvimento dos fundamentos teórico-práticos foram ministradas as oficinas de dança afro, de teatro e de canto coletivo.

Figura 2 - Oficina de Dança Afro

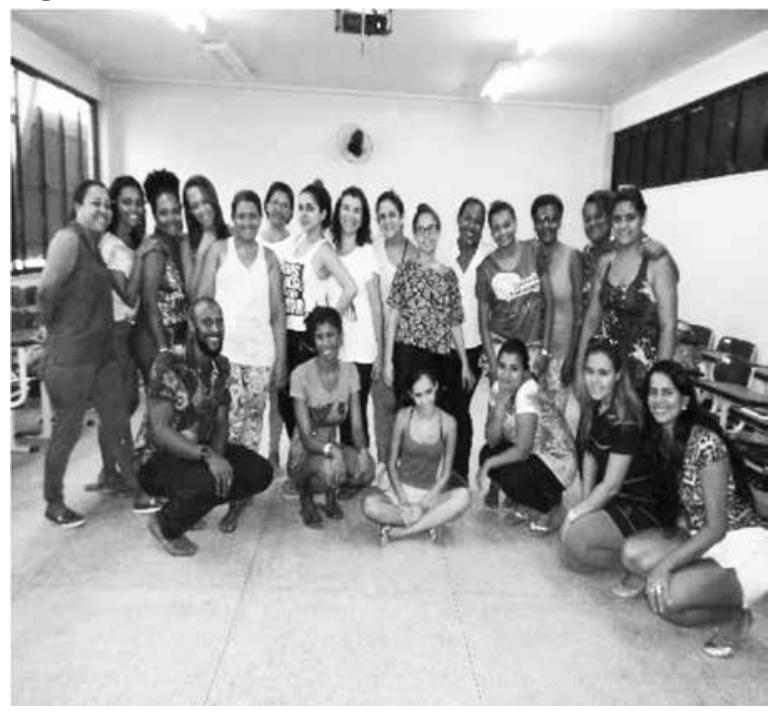

Fonte: Acervo pessoal dos autores. 
Figura 3 - Oficina de Teatro

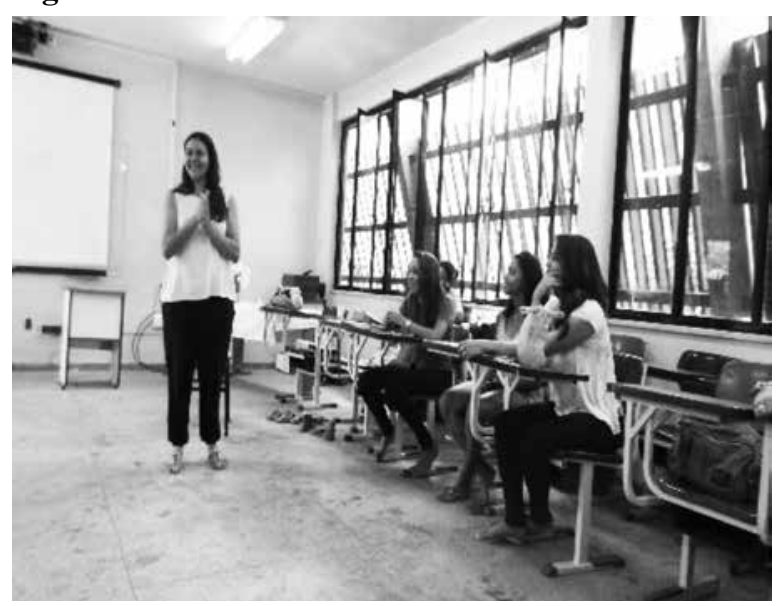

Fonte: Acervo pessoal dos autores.

A oficina de dança afro serviu para a inserção dos discentes no que se refere à Mitologia dos Orixás através dos fundamentos do candomblé e do processo ritualístico estruturante das festas, nas quais há uma ordem específica para a manifestação e a saudação, através da música e da dança, a cada Orixá do panteão Nagô. Já na oficina de dança, os discentes puderam desenvolver uma maior compreensão e conscientização corporal para facilitar a movimentação na performance. Desta forma, saberes desenvolvidos a partir de jogos teatrais, de técnicas vocais e estudos dos arquétipos dos Orixás presentes no repertório selecionado puderam contribuir de forma significativa para a arte de contar a história dos Orixás.

Figura 4 - Contação de Histórias

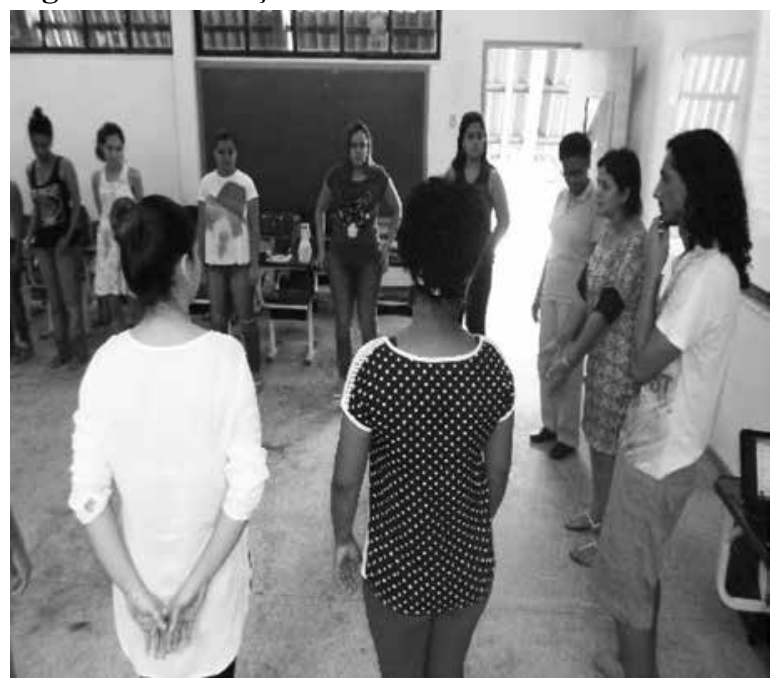

Fonte: Acervo pessoal dos autores.
Figura 5 - Oficina de Canto Coletivo

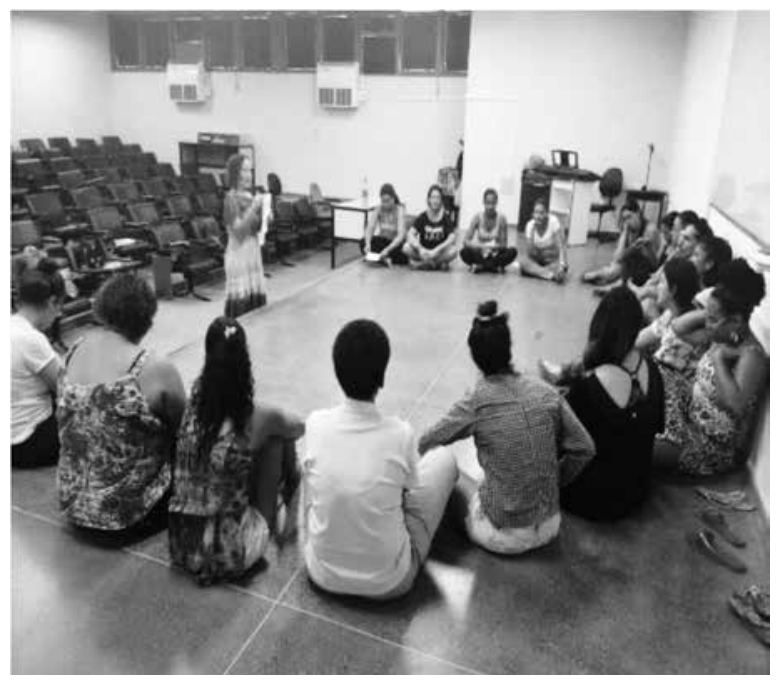

Fonte: Acervo pessoal dos autores.

Por fim, a oficina de canto coletivo, por meio do uso da voz falada e cantada, oportunizou a compreensão da voz não apenas para a arte de contar histórias, mas como uma ferramenta em potencial para a atuação docente. Para tanto, a proposta perpassou conhecimentos teóricos acerca da fisiologia vocal, emissão vocal, funcionamento e tipos de respiração, bem como conhecimentos práticos por meio da experimentação vocal coletiva. É de suma importância para o futuro professor descobrir, conhecer e explorar as suas potencialidades vocais. A partir desse processo de exploração foi possível propor o uso da voz cantada através de um repertório cantado em iorubá, executado em uníssono, com divisão de vozes e fazendo uso também de alguns solos vocais.

Essas oficinas trouxeram oportunidades em que foi possível visibilizar elementos para compreensão das relações entre o professor e o contador de histórias e o tipo de educação gerado pelo fazer híbrido desses ofícios pela via das narrativas de tradição oral, em diálogo com artes como a dança, o teatro e a música. A narrativa tem o poder de ensinar, seja diretamente, como é o caso das fábulas e a moral que elas encerram, seja de maneira subliminar. Através delas são reveladas questões culturais que denotam o modo de pensar de um povo e questões étnicas relativas às raízes que sustentam a formação de qualquer indivíduo. E foi pensando nos ensinamentos que poderíamos extrair das 
narrativas oriundas do nosso legado africano que selecionamos um repertório de histórias registradas em dois livros: Mitologia dos Orixás, de Reginaldo Prandi (2000) e Lendas Africanas dos Orixás, de Pierre Verger (1997).

Cabe salientar que a temática escolhida para este semestre letivo, Mitologia dos Orixás, está diretamente ligada às religiões de matriz africana, consequentemente, tema gerador de polêmicas e preconceitos, dentro e fora da universidade. Todavia, antes de iniciarmos a matrícula da disciplina EDU 925, convocamos os interessados para uma reunião na qual o plano de curso foi apresentado, bem como as principais dúvidas relacionadas aos processos formativos. Ao final da reunião, os interessados na disciplina assinaram um termo de compromisso alegando ter ciência de toda a proposta estruturada num tema relacionado às relações étnico-raciais. Mesmo assim, quando o trabalho começou a ser desenvolvido, quatro alunas se desligaram da turma com o argumento de que os conteúdos ali trabalhados feriam as suas religiões. Depois de alguns dias, recebemos um e-mail desse grupo com o seguinte posicionamento:

Pró, precisamos muito da sua compreensão, pois não vamos apresentar a Mostra Performática dos Orixás, porque não nos sentimos bem fazendo isso. Apesar de saber que seria trabalhado os orixás, não sabíamos que iríamos representá-los. Nos sentimos mal fazendo isso porque somos evangélicas. Se fosse só contar a história, não víamos problemas, mas vestir as cores, cantar suas músicas, dançar, não dá. Nos desculpe. Iremos sair para não atrapalhar. ${ }^{1}$

Acatamos o posicionamento desse grupo sem maiores questionamentos e comunicamos aos alunos que permaneceram na disciplina o ocorrido, abrindo assim um momento para o debate sobre a formação de professores na diversidade e os saberes docentes que influenciam de maneira significativa essa formação. Foi um momento rico, em que esses estudantes de Licenciatura compreenderam como é difícil para o professor se despir das suas crenças em nome de uma Educação que precisa ser laica e respeitosa das diferenças de toda ordem, neste caso, as de ordem religiosa.

\section{Mostra Mitologia dos Orixás: processo de construção}

Apesar de inicialmente o roteiro da mostra ter sido pensado pelas professoras responsáveis do componente EDU 925, ele foi sofrendo alterações a partir das intervenções dos estudantes participantes. As intervenções não se limitaram ao roteiro, foram extensivas ao cenário, ao figurino, aos elementos cênicos, aos movimentos corporais inseridos nas cenas e danças, além da música presente na mostra.

Figura 6 - Participantes da Mostra Mitologia dos Orixás

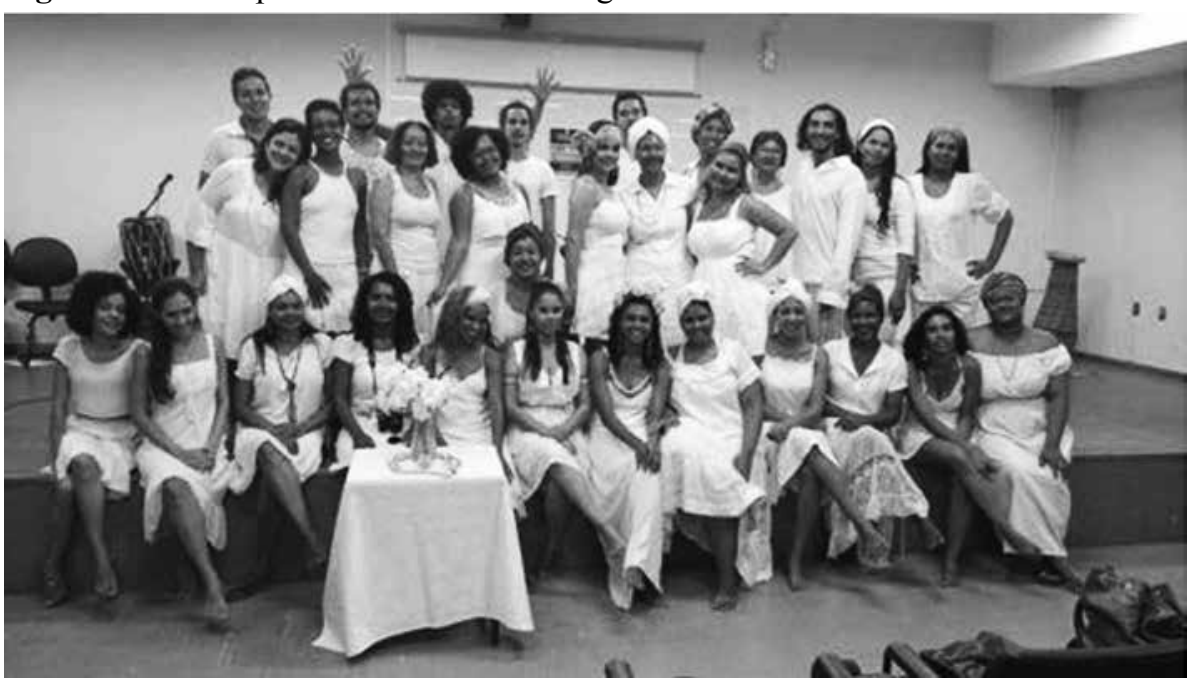

Fonte: Acervo pessoal dos autores.

1 E-mail enviado pelas quatro alunas que deixaram a disciplina, em 04/07/2016. 
Algumas músicas cantadas sofreram ajustes nos arranjos vocais para favorecer a concepção performática, a exemplo do suprimento da divisão de vozes em alguns trechos, assim como as concepções dos acompanhamentos instrumentais com a participação dos solistas das canções executadas. Contudo, a grande interferência musical foi realizada pelos estudantes e professor do componente LET 693. Estes tiveram participação decisiva não só na execução da sonoplastia entre histórias e músicas, mas na seleção de grande parte da trilha sonora, com toques e músicas específicas de alguns Orixás, executadas apenas por eles, como descrito no tópico acima.

Após essas interferências, a partir das histórias de Exu, Oxalá, Iemanjá, Iansã, Oxum, Xango, Obaluaê, Oxóssi e Ogum, narradas por estudantes disponibilizados em duplas ou trios, foram apresentados alguns Orixás. As histórias foram intercaladas por sonoplastias, toques percussivos para determinados Oxalás e movimentos corporais representando determinados arquétipos e algumas danças, apreciadas pelo público composto por professores, estudantes e bolsistas de iniciação à docência do Programa Institucional de Bolsa de Iniciação a Docência (Pibid) do curso de Pedagogia da UEFS. Após a mostra, foi promovida uma roda de conversa com esses sujeitos para oportunizar um momento de discussão e a troca de ideias sobre a temática, seus processos de construção, possibilidades de inserção na educação básica e da realização de trabalho colaborativo na universidade, no âmbito da UEFS, sobretudo entre os Colegiados dos cursos de Música e de Pedagogia.

Figura 7 - Toques dos Orixás

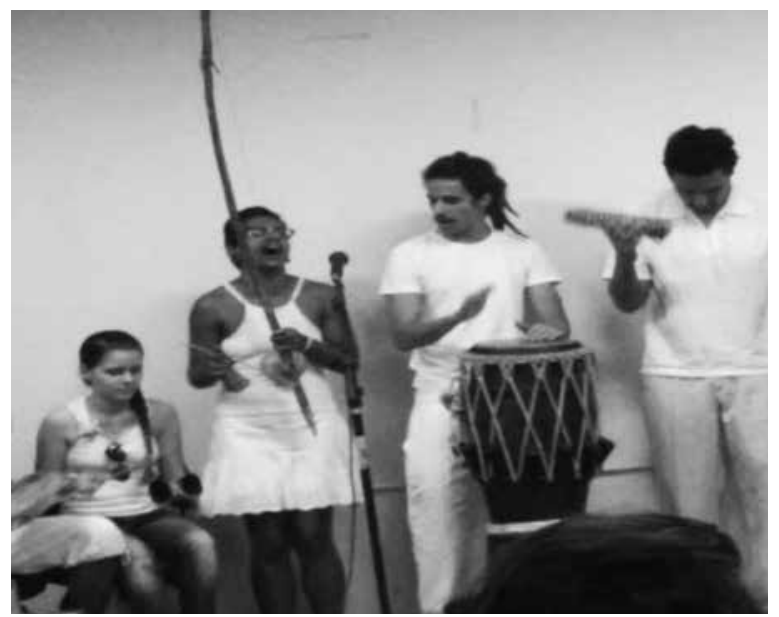

Fonte: Acervo pessoal dos autores.
Figura 8 - Contando histórias dos Orixás

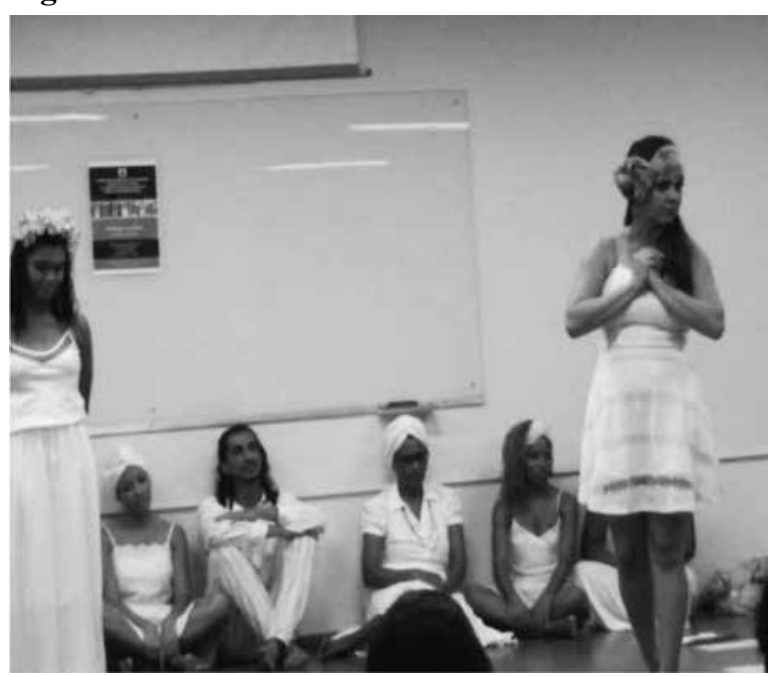

Fonte: Acervo pessoal dos autores.

\section{Considerações finais}

Este trabalho, desenvolvido em uma abordagem interdisciplinar, tendo como principais propulsores disciplinas das áreas de Educação e Música, mostrou-se uma estratégia eficaz para desenvolver uma formação inicial de professores articulando questões referentes às artes e às cultura e história afro-brasileira, com discussões e conteúdos relacionados às temáticas étnico-raciais, através da contação de histórias e da vivência musical.

O estudo dos toques e cantigas de candomblé em um curso de licenciatura em música, é fato, infelizmente, ainda é novo. Os cursos de música no Brasil ainda são, em geral, voltados para o ensino de música erudita, e quando abordam outros repertórios, apenas alguns gêneros de música popular, como o Jazz, a MPB e o choro. Nesse contexto, a música de origem afro-brasileira, bem como as de origem indígena, sertaneja, cabocla e demais manifestações musicais de tradição oral, são completamente marginalizadas e invisibilizadas.

Portanto, há ainda uma enorme lacuna de formação e prática musical para os discentes dos cursos de música, que ao se depararem com a obrigação de abordagem desses conteúdos a partir das Leis $\mathrm{n}^{\mathrm{o}} 11.645 / 2008$ (BRASIL, 2008) e $\mathrm{n}^{\mathrm{o}} 13.278 / 2016$ (BRASIL, 2016b), e da MP n ${ }^{\circ} 746 / 2016$ (BRASIL, 2016a), sentem essa lacuna de uma maneira muito profunda. Através do estudo dos toques, 
das cantigas de orixás e da prática instrumental, a mostra possibilitou aos alunos participantes um contato mais profundo com a música e a cultura afro-brasileira, bem como descortinou os véus do preconceito religioso e musical dos discentes. Nos dias atuais, a inserção de disciplinas e conteúdos que abordem a música de matriz africana e indígena é ainda um grande desafio para os currículos dos cursos de licenciatura em música e acreditamos que iniciativas como a da mostra Mitologia dos Orixás deveriam tornar-se uma atividade curricular constante dos cursos de música e educação, para, aos poucos, preencher essa lacuna formativa.

A mostra evidenciou aos alunos que é possível trabalhar esse repertório - que muitos tinham certo receio por considerá-lo muito complexo ritmicamente - com grupos de alunos da educação básica. O grupo percebeu que toques como o "agueré" e o "ijexá" possuem uma célula rítmica básica simples, de forma que grupos de alunos de crianças e adolescentes podem, a partir de arranjos simples e até mesmo com instrumentos reciclados, executá-los de maneira bastante satisfatória. Além disso, as cantigas de orixás também possuem melodias simples (muitas delas, inclusive, são bastante conhecidas por terem sido incorporadas por artistas a canções populares brasileiras), são geralmente curtas e com forma de responsorial (perguntas e respostas), o que também é um grande facilitador de aprendizado por parte dos alunos.

Através da contação de histórias ficou claro, a partir das oficinas, que assim como cada indivíduo aprende a narrar com a ajuda das potencialidades e características que tem - responsáveis pela construção de um estilo -, também cada criança, jovem ou adulto encontra um jeito próprio de construir seus processos de aprendizagem. Por meio de histórias, as pessoas encontram lentes para enxergar com mais acuidade seu processo de autoconhecimento e de compreensão do momento histórico em que a sociedade se encontra. Para isso, os sujeitos desta pesquisa, 24 (vinte e quatro) estudantes de Licenciatura, iniciantes na arte de contar histórias, compreenderam que precisam portar-se como parceiros, aqueles que propiciam meios e torcem para que a criatividade do outro aflore, condições importantes para o estabelecimento de espaços de confiança entre educadores em formação inicial, o que pode, na compreensão de Matos (2005, p. 112), “[...] ajudá-los a sair do medo, do torpor e da confusão, para entrar em contato com o próprio processo criador".

No contexto dialógico em que os momentos de suspense de uma história aparecem sob forma de tristeza de uma personagem, a angústia de uma situação, o envolvimento acaba ocorrendo, de quem conta e de quem ouve, intensificando a experiência da narrativa e seus impactos no grupo. Essa experiência se deu muitas vezes durante a preparação das histórias a serem contadas na Mostra Performática. Os alunos entenderam que precisavam olhar para o conto como quem olha para um corpo humano e, para fazer o coração desse conto bater forte, careciam de articular as emoções das personagens com as suas próprias emoções, ora emprestando suas experiências para a narrativa, ora buscando na narrativa os sentidos necessários para empreender uma boa performance.

E foi na performance utilizada para dar vida às narrativas presentes no universo das relações étnico-raciais que as questões norteadoras deste artigo foram sendo respondidas. Ao questionar o grupo sobre o impacto da disciplina EDU 925 - Formação de Contadores de Histórias, com a temática da Mitologia dos Orixás, sobre uma possível desmistificação de crenças e medos sobre esse universo, muito estudantes responderam da seguinte forma: ${ }^{2}$

NANÃ: Sim, é impossível negar que há um grande preconceito presente na sociedade quando se trata de religiões de matrizes africanas. Pensa-se logo em coisas ruins, maldades, magia negra etc. Sempre tive receio de até mesmo pronunciar alguns nomes como Exu, Oxalá, entre outros, pois na minha falta de informação traria coisas ruins. Foi maravilhoso conhecer as histórias do mundo Iorubá, foi muito importante pra minha formação não somente profissional [futura pedagoga], mais pra minha formação humana. Entendi de forma prática, através dessa disciplina, o quanto a busca pela informação, o abandono de conceitos prontos, nos proporciona obter novos olhares. Hoje, por onde chego, tenho orgulho de contar as lindas histórias do povo Iorubá.

2 Para manter em sigilo as identidades dos alunos, foram utilizados nomes de Orixás. 
IANSÃ: Até minha adolescência eu era católica e para eles macumba era tudo coisa ruim. Mas quando eu fui crescendo, eu sempre respeitei. E com a disciplina eu fui vendo que é a crença deles, o deus deles... e que preconceito não tem nada a ver. $O$ preconceito com vestimentas e oferendas é grande, mas não tem nada a ver, é o jeito que eles têm de cultuar os seus deuses.

IEMANJÁ: Sim, a disciplina EDU 925 ampliou o meu olhar sobre a cultura e a religião de matriz africana, me enriquecendo culturalmente com novas informações sobre o universo dos orixás.

Quando questionados sobre se a partir da experiência estética sensorial de escuta e narração de histórias em EDU 925, no semestre especial de 2016, foi possível valorizarem as relações étnico-raciais na UEFS, a turma foi unânime em afirmar que sim, que a disciplina havia mudado a forma que tinham de se relacionar com a temática e que o respeito aprendido durante o período de constituição daquele repertório foi essencial para que essa valorização se estabelecesse:

NANÃ: Além de valorizar e entender a importância do respeito, e a necessidade das relações étnico-raciais na UEFS, a disciplina me fez pensar o quanto esse assunto deve ser cada vez mais levado a sério e debatido dentro da Universidade, pois o ambiente acadêmico, lugar onde deveria haver respeito à diversidade, muitas vezes acaba sendo lugar de 'reforço'ao preconceito. Acredito que assuntos como este devem ser discutidos em sala, como instrumento de formação, visando formar cidadãos conscientes e respeitosos uns com os outros.

Ao provocarmos o grupo com o contato com as artes nas oficinas da disciplina EDU 925 - dança, teatro, música e contação de histórias -, e a sua importância na formação inicial de professores e sobre um possível desdobramento nas salas de aula da Educação Básica, o grupo também foi coeso ao afirmar que percebem o quanto o professor ganha com a experiência artística tão pouco trabalhada pela universidade:

OXUM: É de riquíssima importância. Quebra a timidez e o professor em formação vê que existem maneiras diversificadas de mostrar o conteúdo ao nosso aluno, porque aprendemos na UEFS a fazer desse outro jeito. A aula de canto foi muito importante porque ajudou a gente a cantar junto com nosso aluno. Professor também tem que ser múltiplo, ele tem que saber cantar, representar e fazer tudo.

OGUM: A arte é fundamental para conhecermos a história e o universo que nos cerca, nos faz ampliar o olhar para o mundo e para dentro de nós mesmos. Para mim a experiência foi incrivel, a vida acadêmica precisa incluir nos currículos dos estudantes das licenciaturas uma formação acadêmica com formação para as artes. Na educação básica a arte é fundamental instrumento para que as crianças aprendam o universo que as cercam. A arte educa: música, literatura, poesia, dança e eventos culturais, visitas aos museus, entre outros são importantes elementos para formação das crianças.

E é na contramão dessa divisão entre lazer e labor que se encontra a arte de contar histórias, provocadora de alegria no processo educativo, localizada no cerne de uma educação sustentada pelo afeto e pela sensibilidade, responsável, ao lado das outras artes, pela construção de uma poética dos processos de ensino e aprendizagem. Todavia, para que essa alegria seja reconhecida no processo educativo, é preciso que o professor se reconheça como alguém que, ao mesmo tempo que educa, é também educado, já que vive num círculo de relacionamentos. Esse círculo, segundo Freire (1997, p. 26), permite “[...] a presença de espíritos livres, criativos, libertos da cadeia de comando que assola e conforma nossa educação. [...] percebe que ensinar e aprender não pode se dar fora da procura, da boniteza e da alegria [...] e que a educação deve ser estética e ética".

\section{REFERÊNCIAS}

ALMEIDA, L. J. M. As questões étnico-raciais na escola. In: SEMINÁRIO DE PRÁTICAS PEDAGÓGICO-MUSICAIS ESCOLARES, 1., 2014, Feira de Santana. Anais... Feira de Santana: Universidade Estadual de Feira de Santana, 2014. p. 17-20.

AMARAL, Ligia Assumpção. Sobre crocodilos e avestruzes: falando de diferenças físicas, preconceito e sua su- 
peração. In: AQUINO, Julio Groppa (Org.). Diferenças e preconceito na escola: alternativas teóricas e práticas. 5. ed. São Paulo: Summus, 1998. p. 11-30.

Presidência da República. Decreto no 129, de 22 de maio de 1991. Promulga a Convenção $\mathrm{n}^{0}$ 159, da Organização Internacional do Trabalho - OIT, sobre a Reabilitação profissional e Emprego de Pessoas Deficientes. Brasília, DF, 1991. Disponível em: <http://www.planalto.gov.br/ccivil_03/decreto/1990-1994/D0129.htm>. Acesso em: 17 dez. 2016.

Presidência da República. Lei n⿳0 $\mathbf{1 1 . 6 4 5}$, de 10 de março de 2008. Altera a Lei no 9.394, de 20 de dezembro

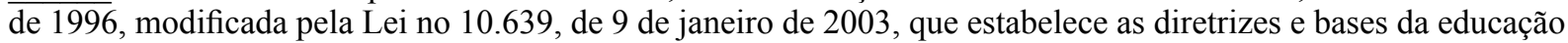
nacional, para incluir no currículo oficial da rede de ensino a obrigatoriedade da temática "História e Cultura Afro-Brasileira e indígena. Brasília, DF, 2008. Disponível em: <http:/www.planalto.gov.br/ccivil_03/_ato20072010/2008/lei/111645.htm>. Acesso em: 17 dez. 2016.

Presidência da República. Medida Provisória no 746, de 22 de setembro de 2016. Brasília, DF, $2016 a$. Disponível em: <https://www.planalto.gov.br/ccivil_03/_Ato2015-2018/2016/Mpv/mpv746.htm>. Acesso em: 18 dez. 2016.

Presidência da República. Lei no 13.278, de 02 de maio de 2016. Altera o § 6o do art. 26 da Lei no 9.394,

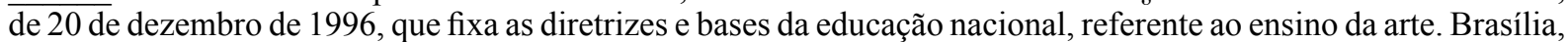
DF, 2016b. Disponível em: <http://www.planalto.gov.br/ccivil_03/_ato2015-2018/2016/lei/113278.htm>. Acesso em: 18 dez. 2016.

CAMPBELL, Patricia Sheehan. Songs in their heads: music and its meanings in children's live. Oxford: Oxford University Press, 2003.

DORING, Katharina. Samba de roda e ensino-aprendizagem em três recortes temporais e espaciais. In: CONGRESSO NACIONAL DAASSOCIAÇÃO BRASILEIRA DE EDUCAÇÃO MUSICAL (ABEM), 22., 2015, Natal. Anais... Natal: ABEM, 2015.

FORQUIN, Jean-Claude. Escola e cultura: as bases sociais e epistemológicas do conhecimento escolar. Tradução de Guacira Lopes Louro. Porto Alegre: Artes Médicas, 1993.

FREIRE, Paulo. Pedagogia da autonomia: saberes necessários à prática educativa. São Paulo: Paz e Terra, 1997.

GOMES, Nilma Lino. Relações étnico-raciais, educação e descolonização dos currículos. Currículo sem fronteiras, v. 12, n. 1, p. 98-109, jan. 2012.

HIKIJI, Rose Satiko Gitirana. A música e o risco. São Paulo: Edusp/Fapesp, 2006.

INSTITUTO BRASILEIRO DE GEOGRAFIA E ESTATÍSTICA (IBGE). Conteúdo Histórico: Brasil - 500 anos de povoamento. Disponível em: <http://brasil500anos.ibge.gov.br/>. Acesso em: 06 de dez. 2016.

KLEBER, Magali Oliveira. A prática de educação em ONGs: dois estudos de caso no contexto urbano brasileiro. Curitiba: Appris, 2014.

LÜHNING, Angela. Música: coração do candomblé. In: Revista USP, São Paulo, n. 7, p. 115-124, set./nov. 1990.

MATOS, Gislayne Avelar. A palavra do contador de histórias: sua dimensão educativa na contemporaneidade. São Paulo: Martins Fontes, 2005.

NETTL, Bruno. The study of ethnomusicology: thirty-one issues and concepts. 2. ed. Illinois: University of Illinois Press, 2005.

ONG, Walter. Oralidade e cultura escrita. Campinas, SP: Papirus, 1993.

PRANDI, Reginaldo. Mitologia dos Orixás. São Paulo: Companhia das Letras, 2000.

QUEIROZ, Luis Ricardo. A música como fenômeno sociocultural: perspectivas para uma educação musical abrangente. In: MARINHO, Vanildo Mousinho; QUEIROZ, Luis Ricardo (Org.). Contexturas: o ensino das artes em diferentes espaços. João Pessoa: Editora da UFPB, 2005. p. 49-66.

ROSEMBERG, Fúlvia. Raça e desigualdade educacional no Brasil. In: AQUINO, Julio Groppa (Org.). Diferenças e preconceito na escola: alternativas teóricas e práticas. 5. ed. São Paulo: Summus, 1998. p. 73-93.

RUBIRA, Fabiana de Pontes. Contar e ouvir estórias: um diálogo de coração para coração acordando imagens. 
2006. Dissertação (Mestrado em Educação) - Universidade de São Paulo (USP), São Paulo, 2006.

SALES, M. Performance musical na escola. In: Seminário de Práticas Pedagógico-Musicais Escolares, 1., 2014, Feira de Santana. Anais... Feira de Santana: Universidade Estadual de Feira de Santana, 2014. p. 20-22.

SANSONE, Lívio. Negritude sem etnicidade: o local e o global nas relações raciais, culturas e identidades negras no Brasil. Tradução Vera Ribeiro. Salvador: Edufba/Pallas, 2003.

SANTIAGO, Renan; IVENICKI, Ana. Multiculturalismo na formação de professores de música: o caso de três instituições de ensino superior da cidade do Rio de Janeiro. Opus, v. 22, n. 1, p. 211-236, jun. 2016.

SOARES, Rafael. Traficantes proíbem candomblé e até roupas brancas em favelas. O Globo, Rio de Janeiro, 10 det. 2013. Disponível em: <http://oglobo.globo.com/rio/traficantes-proibem-candomble-ate-roupa-branca-em-favelas-9892892>. Acesso em: 20 dez. 2016.

SWANWICK, Keith. Ensinando música musicalmente. Tradução de Alda Oliveira e Cristina Tourinho. São Paulo: Moderna, 2003.

VERGER, Pierre Fatumbi. Lendas africanas dos orixás. 4. ed. Salvador: Corrupio, 1997.

Recebido em: 16/01/2017

Aprovado em: 06/04/2017 